\title{
REVISÃO SISTEMÁTICA SOBRE A AÇÃO DO LICOPENO PERANTE AO ENVELHECIMENTO CUTÂNEO EM NUTRICOSMÉTICOS
}

\author{
Edilaine Cristina Zago ${ }^{1}$
}

Cristina Maria Franzini ${ }^{2}$

RESUMO: Nos últimos anos, surgiu uma nova consciência para melhorar a qualidade da saúde e reduzir os riscos à saúde e os custos médicos. Isso tem contribuído para o desenvolvimento e aumento do uso de alimentos ativos, nutracêuticos e nutri cosméticos. Por isso e pelo aumento de estudos e pesquisas na área, as revisões são importantes para abranger argumentos baseados em evidências científicas. Com isso em mente, o objetivo deste estudo foi examinar a relação entre o uso de nutri cosméticos do tipo licopeno. O presente estudo foi desenvolvido a partir de uma revisão da literatura, que incluiu revisões da literatura sobre o uso de nutri cosméticos no envelhecimento cutâneo. No que diz respeito ao envelhecimento cutâneo, os principais nutri cosméticos são comprovados por aqueles que contam com elementos antioxidantes. Todos demonstraram que os efeitos antioxidantes ajudam a reduzir os sintomas do envelhecimento. Ao final desta revisão, reforçamos a ideia de que os suplementos nutricionais contribuem para o tratamento de alimentos saudáveis.

Palavras-chave: Estética. Envelhecimento. Licopeno.

\section{INTRODUÇÃO}

Cientistas de todo o mundo há muito investem em pesquisas e buscam respostas para encontrar uma solução para o rejuvenescimento da pele. A pele, ao longo do tempo, sofre mudanças biológicas e físicas, que por sua vez afetam o comportamento humano e social. Isso cria no mundo da educação e no mercado da beleza, um interesse duradouro em estudar os efeitos do envelhecimento na pele, e na fabricação de produtos que interrompam esse processo, buscando conter a mudança emergente (Pais, 2012).

\footnotetext{
I Graduanda em Farmácia pela instituição FHO Fundação Hermínio Ometto. Experiência profissional atuou como supervisora administrativa na empresa Droga Raia S/A.E-mail: edilainecristinazago@gmail.com.

2 Doutorado em Ciências Farmacêuticas - Universidade Estadual Paulista - UNESP Araraquara. Mestrado em Ciências Farmacêuticas - Universidade Estadual Paulista - UNESP Araraquara. Professora e orientadora FHO Fundação Hermínio Ometto.
} 
A principal causa do envelhecimento cutâneo é encontrada no acúmulo de radicais livres produzidos pelo próprio metabolismo celular ou por fontes externas, como estresse, alimentação inadequada, tabaco e luz solar. "Os radicais livres são reconhecidamente uma das principais causas do envelhecimento e das doenças degenerativas relacionadas com a idade" (PUJOL, 20II).

O corpo, por natureza, se protege da ação dos radicais livres. Porém, esse sistema de proteção, ao longo do tempo, não funciona bem. A principal forma de obter antioxidantes é por meio das reações químicas do corpo aos alimentos. Os principais antioxidantes da dieta são outras vitaminas (A, C e E), carotenoides, flavonóides e selênio (Parrininha, 2014).

Uma das melhores maneiras de prevenir o envelhecimento é usar antibióticos que podem prevenir o dano oxidativo, eles se combinam com os radicais livres antes de reagirem com as moléculas orgânicas. No entanto, uma vida agitada é uma característica da sociedade moderna, estimulando as pessoas a fazerem uma dieta pouco saudável e a perderem nutrientes essenciais. As deficiências nutricionais, incluindo antioxidantes, são causa de uma série de consequências para a saúde e sociais, contribuindo inclusive para o processo de envelhecimento. De acordo com essa visão, há necessidade de alimentos adicionais. No mercado atual há o surgimento de uma classe de produtos, os nutri cosméticos, conhecidas como "cápsulas de beleza". O consumo oral, encontrado na forma de comprimidos, líquidos e alimentos, mais recentemente como doces e salgadinhos, é composto por uma série de substâncias que prometem tratar o corpo interna e externamente. Esses produtos combinam nutrientes e beleza para suprimir o organismo de nutrientes essenciais que auxiliam no processo de proteção ou redução dos sintomas do envelhecimento cutâneo (BRANDÃO, 2010).

Os nutri cosméticos baseiam-se na ideia de que a chave para melhorar a aparência e alcançar uma boa saúde geral são as palavras: "a beleza vem de dentro" seus efeitos podem ser vistos em diferentes níveis: na pele tão antioxidante quanto um moderno para processos inflamatórios e resposta imune (Melo, et al. 2014). 
Segundo dados da consultoria Euromonitor International (apud ANUNCIATO; TAKAHASHI; FILHO, 20II, p. 42), o mercado de nutri cosméticos foi estimado em US \$4, I bilhões em 2009, sendo US \$2,7 bilhões em suplementos e US \$ I,7 bilhão em participação no mercado de alimentos e bebidas.

Os carotenoides, que precedem a síntese da vitamina $\mathrm{A}$, geralmente são sintetizados pelas plantas. $\mathrm{O}$ corpo humano converte os carotenoides dos alimentos em retinol e seus metabólitos. Dos 600 carotenoides encontrados na natureza, apenas um pequeno número é encontrado nos alimentos e não é encontrado, a saber: $\beta$ caroteno, $\alpha$-caroteno, licopeno, luteína, zeaxantina e $\beta$-criptoxantina. Geralmente ocorre na epiderme (oculta pelas glândulas dominantes) e na derme (SILVA, 2015).

O mercado de nutri cosméticos representa uma importante área das indústrias alimentícia, cosmética e farmacêutica, seus limites entre as indústrias mais próximas. Como o mercado de nutricosméticos vem crescendo de forma constante, há a necessidade de aumentar o conhecimento e a expertise de especialistas na área da beleza para que possam utilizar esses produtos de forma equilibrada e consistente. Além disso, a importância de se discutir a questão do envelhecimento da pele e a eficácia dos nutri cosméticos é bem-vinda, visto que a pele é muito importante na beleza e na saúde, o envelhecimento é um fator que afeta negativamente a sua autoestima e afeta a qualidade de vida das pessoas. Portanto, este estudo tem como objetivo analisar a utilização dos licopenos em produtos disponíveis no mercado como os nutri cosméticos com o objetivo de combater o envelhecimento cutâneo

\section{METODOLOGIA}

As revisões literárias são feitas em dados Medline, SciElo, Pubmed, Cochrane. Este trabalho será baseado em um processo de pesquisa pública, que se caracterizam por um exame das teorias de ideias já analisadas e publicadas, disponibilizadas ao público, não escritas ou informatizadas, por meio da análise de artigos científicos, revistas, livros, entre outros. Todo trabalho científico precisa ser feito com base na pesquisa bibliográfica, pois aproxima o pesquisador do tema 
pesquisado, permitindo-lhe focar no que está sendo pesquisado sobre o assunto (GERHARDT; SILVEIRA, 2009).

Na prática, a pesquisa pode ser considerada suficiente, pois não afeta a representação de valores, mas sim o nível e a profundidade de compreensão do tema escolhido na análise e relevância das informações obtidas em dados de pesquisas bibliográficas e laboratoriais. Esta abordagem visa destacar os motivos de certas afirmações, não se preocupar em divulgar dados estatísticos para embasar seu ponto de vista, mas sim analisá-los com mais detalhes. O objetivo deste tipo de pesquisa é fornecer dados em profundidade, que possibilitem a criação de novos dados a partir destes (GERHARDT; SILVEIRA, 2009)

\section{REVISÃO DE LITERATURA}

\section{I ENVELHECIMENTO CUTÂNEO}

Com o tempo, o corpo, órgãos e tecidos envelhecem, com a pele ficando mais exposta, em decorrência do qual o envelhecimento é mais pronunciado. $O$ envelhecimento da pele ocorre como resultado de mudanças no organismo causadas pela exposição excessiva ao sol e dieta inadequada (AZEVEDO et al., 2018).

A pele é composta por proteínas, sais minerais, carboidratos e cerca de $70 \%$ de água, criando uma grande barreira de proteção contra agentes externos. Suas principais funções são a proteção corporal, regulação do calor, armazenamento de gordura, respiração e cicatrização (DOS SANTOS; DE OLIVEIRA, 2014).

O envelhecimento da pele está associado à degeneração e depressão e à falta de homeostase celular em relação à regeneração. Harman descreveu o envelhecimento como perda de emprego e adaptação (WATANABE, 2013). Os principais sintomas do envelhecimento cutâneo ocorrem devido à falta de luz, ressecamento e firmeza da pele, o que provoca o aparecimento de rugas finas e finas. Esses sintomas ocorrem devido a fatores externos e genéticos (DE OLIVEIRA et al., 2019). 
O envelhecimento da pele é dividido em dois tipos: interno e externo, primeiro causado pela genética e por alterações no sistema endócrino que ocorrem ao longo do tempo (BOTAZINI et al., 2016). O fator extrínseco, por outro lado, é devido às mudanças acumuladas nos agentes da pele ao longo do tempo, como sujeira, tabagismo e exposição ao sol, que é um fator importante em muitas condições de envelhecimento precoce (ALVES; ESTEVES; TRELLES, 2013).

Em muitos casos, o envelhecimento prematuro é causado pela radiação ultravioleta. Os raios UVA atingem o tecido conjuntivo da derme, que é a parte mais profunda da pele, e podem causar câncer. Por outro lado, a radiação UVB atinge a epiderme e pode causar queimaduras e danos indiretos ao DNA. Esse dano é causado pela formação de radicais livres (GONÇALVES et al., 2019).

O envelhecimento da pele causa alterações na epiderme, derme e anexos. $\mathrm{Na}$ epiderme, ocorrem alterações na estrutura e no tamanho das células, resultando em sua durabilidade, isso se deve à redução dos melanócitos, células de Langerhans e ao amolecimento do trato derme epidérmico. Na derme há falta de fibroblastos, vasos sanguíneos e mastócitos, resultando em atrofia e perda de volume do tecido (FIGUEIREDO, 2014). Na fase de envelhecimento, a derme produz menos colágeno e desenvolve fibras isoladas e disfuncionais, com produção anormal de elastina de baixo grau e vascularização. (ANDRADE, 2014).

\subsection{SAÚDE DA PELE E ESTÉTICA}

A pele possui três camadas, a Epiderme, Derme e Hipoderme. A epiderme é dividida em camadas chamadas de queratinócitos (células epiteliais estratificadas), essas células vão se separar da base basal, se separam ainda mais quando atingem a superfície, perdem seus núcleos e formam um grupo de queratina que faz com que a pele previna e proteja a pele de bactérias e a perda de eletrólitos e fluidos (NAVARRO, 2016).

A derme é composta por filamentos de proteínas que são conectados a uma rede externa à célula, de modo que a camada extensível é altamente resistente à 
agressão. A hipoderme é a camada final, também conhecida como tecido adiposo ou camada subcutânea, responsável pela produção e liberação das adpocinas, devido à sua função de economia de energia. (ROCHA; SANTORI; NAVARRO, 2016).

A aparência da pele é diretamente afetada por fatores externos, como produtos químicos tóxicos, radicais livres, radiação ultravioleta e alérgenos que podem levar ao envelhecimento da pele e possível inflamação. Rugas, por exemplo, são as linhas de exposição à pele decorrentes do processo de envelhecimento da pele, resultando em uma perda da força natural decorrente de uma redução das estrias, rigidez do colágeno, diminuição da função muscular e diminuição do tom de pele causando pele seca (TESTE; NARDINO; PIVATO, 2017).

Outro fator que influencia o processo de envelhecimento é a perda de colágeno, uma proteína encontrada em grandes quantidades no corpo humano. Os fibroblastos incluem colágeno e elastina reduzida devido ao excesso de exposição ao sol e fatores externos que levam ao aparecimento de rugas e perda de crescimento da pele (TESTON; NARDINO; PIVATO, 2017).

Os antioxidantes podem ajudar diretamente a desacelerar o processo de envelhecimento e melhorar a saúde da pele, trabalhar para combater os radicais livres, doar elétrons para retardar o início dos processos oxidativos, reduzir os danos às moléculas e estruturas celulares. Outros antioxidantes que podem ser encontrados nos alimentos são: vitaminas C, E e A, flavonóides e carotenóides (BRASIL, 2015; MASHORCA et al., 2016).

Uma dieta ativa é uma dieta rica em nutrientes e que pode atuar no metabolismo do corpo, e os nutrientes ativos desempenham um papel no crescimento, desenvolvimento, cuidado e outras funções corporais. Uma dieta ativa também é benéfica para melhorar a saúde da pele. Sua composição pode ajudar a manter os níveis recomendados de triglicerídeos, proteção celular contra radicais livres, controle da microbiota intestinal, desde que esses usos estejam associados a hábitos de vida saudáveis, outros exemplos desses alimentos são: soja e derivados, 
óleos, frutas, vegetais, leguminosas, folhas verdes (ROCHA; SANTORI; NAVARRO, 2016)

\subsection{NUTRICOSMÉTICOS}

Verificou-se na quantidade certa de nutrientes no início da temporada que uma dieta nutritiva pode afetar a integridade e a beleza da pele. Porém, o estilo de vida e os maus hábitos alimentares de muitas pessoas dificultam o uso de alimentos integrais e balanceados, a fim de desenvolver estratégias mais diversas para atender às necessidades dos consumidores. Surge assim a mais recente combinação da indústria cosmética com a indústria alimentar: os nutri cosméticos. Muitas vezes é referido como "pílulas de beleza" ou "cosméticos orais", os nutri cosméticos afirmam dar "beleza por dentro". Em outras palavras, alguns descrevem os nutri cosméticos como uma combinação de nutracêuticos e cosméticos (Cosmeceuticals Market, 2018).

Existe uma tendência que está mudando o conceito de cuidados com a pele, que é um suplemento alimentar que valoriza a sua aparência, os nutri cosméticos.

Tais suplementos seguem o conceito de "beleza de dentro para fora", que trata da aquisição de vitaminas e oxidantes para uma aparência saudável e bonita da pele (FREIRE, 2016).

Os nutri cosméticos podem ser considerados suplementos nutricionais compostos por vitaminas, aminoácidos, proteínas e / ou botânicos actânicos e antioxidantes. Portanto, são utilizados para retardar o envelhecimento, melhorar a firmeza da pele e a proteção solar (IMATOS, 2014).

Os nutri cosméticos são o resultado de uma combinação das indústrias cosmética e alimentícia. Essas fusões ocorreram em diversos setores, identificando o sindicato como forma de atender às novas demandas dos consumidores, como as indústrias alimentícia, cosmética e médica (FREIRE, 2016).

A ideia é tratar a pele internamente e no momento é possível corrigir alguns defeitos do nosso corpo com esse tipo de maquiagem. O objetivo deste novo tipo de 
suplemento, em relação à pele, é protegê-la dos efeitos do sol, promover o relaxamento e reduzir os sinais externos de envelhecimento. Portanto, esses aditivos também podem ser incorporados em produtos voltados para a prevenção de imagens (Brandão, 2010).

Eles são mais benéficos do que os anéis cosméticos, pois podem beneficiar toda a pele. No entanto, os maiores benefícios são observados quando esses suplementos são usados em conjunto com cosméticos sem receita. Os princípios básicos usados neste tipo são:

ácido hialurônico. O glicosaminoglicano não sulfatado é um dos ingredientes mais recentes introduzidos nos nutri cosméticos. Possui ação calmante, rejuvenescedora e antirrugas. Está amplamente disponível na pele e ajuda a manter mais de rooo vezes o peso da água dentro das células da pele, tornando-se um excelente hidratante. $\mathrm{Na}$ derme, regula o equilíbrio da água, a pressão osmótica, a troca iônica e atua como um filtro e fortalece as estruturas da pele por meio de interações eletrostáticas. Tudo isso leva a um aumento da maciez da pele e à diminuição das rugas. (Monteiro, 2014)

Colágeno. É um componente natural das proteínas da pele; $O$ colágeno tipo é o mais abundante na derme. Cerca de um terço da proteína do corpo é composta de colágeno, que é encontrado nos ossos, músculos e tecidos. Colágeno, elastina e queratina dão à pele sua força, firmeza e estrutura. $O$ corpo produz colágeno naturalmente, mas esse produto é reduzido gradualmente como parte do processo natural de envelhecimento. Nos últimos anos, a indústria começou a fazer suplementos de colágeno oral. Os suplementos de colágeno podem ajudar a melhorar a aparência da pele, atenuar linhas finas e rugas, remover manchas e aumentar a firmeza da pele (Zague, 20II).

$\beta$-caroteno e licopeno. Esses compostos, conforme mencionado acima, pertencem à categoria dos carotenoides. Estudos confirmaram que a alimentação prolongada com essas atividades melhora a função imunológica e aumenta ligeiramente a pequena dose de eritema (Gilaberte, 2010). 
O B-caroteno possui fortes propriedades antioxidantes e, portanto, tem potencial para reduzir e proteger sua aparência, além de melhorar a absorção de água. O licopeno é roo vezes mais eficaz do que a vitamina $E$ no combate às ROS. Esse carotenoide deixa a pele mais hidratada e macia, e ainda reduz o efeito das rugas e feições na pele (Brandão, 2010).

Lactobacillus. São probióticos e, portanto, interagem diretamente com o epitélio intestinal para formar uma combinação de mensageiros, que são transportados por uma corrente sanguínea até a pele e, dessa forma, ativam a defesa celular. Lactobacillus johnsonii foi o primeiro probiótico clínico a exibir uma exposição eficaz da pele à radiação ultravioleta. Outros estudos também mostraram que a interação deste probiótico com carotenoides como $\beta$-caroteno e licopeno levou a uma detecção mais rápida da função das células de Langerhans após a exposição aos raios ultravioleta, pequenas alterações na morfologia e contagem de células e um pequeno número de células inflamatórias prejudicam a pele proteção do corpo. (Teixeira, 2010).

Resveratrol. Um flavonoide, previamente descrito, possui forte atividade antioxidante (Brandão, 2010).

Zinco. Este ferro, junto com as vitaminas C e E, ajuda o sistema imunológico do corpo a construir colágeno e elastina, melhorando assim a aparência da pele sensível (Brandão, 2010).

Gordura sem açúcar. Este tipo de ácido faz parte da barreira cutânea e está envolvido na formação e formação das membranas. Este grupo inclui o ômega 3 e 6, como os nutri cosméticos mais utilizados. Eles são ácidos graxos essenciais e, portanto, não são absorvidos pelo corpo (Nutri cosméticos)

Vitaminas C e E. Estes são importantes para este tipo de suplemento, pois possui ótimas propriedades antioxidantes, conforme mencionado acima, e assim auxilia no combate ao estresse oxidativo, causado pelos raios ultravioletas (Nutri cosméticos). 
Temporada. A IL-selemetionina, produzida a partir do selênio, tem a capacidade de reduzir os radicais livres e tem ação antioxidante (Nutri cosméticos).

Extrato de mirtilo seco (Vaccinium myrtillus). Antho é ativo com 50\% de antocianinas. O processo de extração é patenteado e reduz o desperdício e as substâncias químicas contidas nesta extração. É calculado antes da liberação do chá verde em termos de poder antioxidante. Também tem uma boa nutrição para o estômago e intestinos (Nutri cosméticos).

Lacto-lycopene ${ }^{\circledR}$. O ingrediente ativo, L'Oreal, é um composto de proteínas do leite contendo licopeno, aumentando assim sua disponibilidade. Esta lei ativa estimula a regeneração celular e promove a produção e proliferação de lipídios através da epiderme (Nutricosméticos).

Liberação de Polipodyum leucotomos. E, como mencionado acima, isso é extraído da planta da família da samambaia e tem propriedades antioxidantes muito fortes. Dentre todas as funções protetoras introduzidas, protege a pele nas áreas escuras, e contribui para a proteção das rugas e firmeza da pele (Nutricosméticos).

Cacau em pó orgânico. É rico em polifenóis, principalmente flavonóides. A sua introdução aumenta o fluxo sanguíneo para os tecidos subjacentes e subcutâneos, aumenta o tamanho da pele e consequentemente a sua plenitude, aumenta a densidade da epiderme, reduz a firmeza e descamação da pele. Também tem a capacidade de reduzir os radicais livres causados pela luz solar, evitando que a pele fotografe (Nutricosméticos).

Existem vários ingredientes ativos que podem ser adicionados ao nutri cosmético. Assim como os protetores solares, os nutri cosméticos, que ainda são um tipo de protetor solar oral, também são propensos a compostos, especialmente antioxidantes

Os efeitos da luz solar e melhoram a aparência da pele. Esses nutrientes costumam aumentar a tolerância da pele à luz, mas devem atuar como complemento 
ou elogio aos produtos tópicos, principalmente para pessoas com pele muito sensível ou irritada (Nutricosméticos).

Atualmente existe no mercado uma ampla gama de nutri cosméticos publicamente disponíveis, consistindo em várias associações de princípios ativos, dependendo do efeito para o qual são feitos. Alguns desses suplementos podem ser usados como um tratamento preventivo e curativo de fotoenvelhecimento. Por exemplo, temos as adições dos bem conhecidos suplementos Innéov ${ }^{\circledR}$, Heliocare ${ }^{\circledR}$ e Purelogical ${ }^{\circledR}$.

Innéov ${ }^{\circledR}$ é uma das marcas mais conhecidas para este tipo de suplemento, atualmente com suplemento anti-celulite antienvelhecimento, composto por um poderoso sistema antioxidante, selênio contendo vitamina $\mathrm{C}$, e um concentrado alimentar saudável, que contém uma combinação de $\beta$-caroteno e -Lacto-licopeno (Innéov, 2021)

Heliocare ${ }^{\circledR}$ é uma variedade de produtos tópicos e orais baseados na proteção da pele dos danos do sol e do envelhecimento. A Scope usa Fernblock, uma tecnologia baseada no extrato de Polypodium leucotomos (Heliocare, 202I).

Purelogical ${ }^{\circledR}$ é um produto que se concentra principalmente no uso de colágeno e contém sua variedade, ingredientes orais à base de colágeno e outros produtos de aplicação tópica (Purelogial, 202I).

Esta categoria de produtos inclui suplementos nutricionais, suplementos dietéticos e alimentos, alimentos geneticamente modificados, produtos de base vegetal e alimentos processados como sorgo, sopas e bebidas (Defelice, 1995)

. Eu assumi a forma de comprimidos, pílulas, líquidos ou alimentos ", com o objetivo de fazer a pele, cabelo e unhas (Taeymans, 2014).

este conceito fornece um elo importante entre ingredientes de alimentos saudáveis no estágio de edifícios de saúde. Os principais ingredientes usados para esse fim são: isoflavonas de soja, -luteína, licopeno, vitaminas (A, B6, E), ácidos 
graxos ômega-3, $\beta$-caroteno, coenzima $Q$, resveratrol e selênio, alguns dos quais estão listados na imagem I abaixo. As causas desses produtos são: foto proteção, hidratação, antienvelhecimento e ação, reparo do cabelo e dieta ok Nutrição, crescimento do cabelo e perda de peso (SCCS, 2014)

Figura I: Materiais utilizados em nutri cosméticos e ações cosméticas comprovadas.

\begin{tabular}{|c|c|}
\hline $\begin{array}{c}\text { Substâncias utilizadas nos } \\
\text { nutricosméticos }\end{array}$ & Ação cosmética proposta \\
\hline $\begin{array}{c}\text { Licopeno. luteína. B-caroteno e } \\
\text { Selénio }\end{array}$ & $\begin{array}{c}\text { Melhoram a densidade e espessura cutânea, a rugosidade e } \\
\text { a descamaçấo cutânea } 33\end{array}$ \\
\hline Picnogenol & $\begin{array}{c}\text { Redução da área do melasma e da intensidade da } \\
\text { pigmentaçăo da pele } 33\end{array}$ \\
\hline Vitamina C e Vitamina $E$ & $\begin{array}{c}\text { Antioxidantes celulares com efeito protetor contra a } \\
\text { radiaçâo UVA e UVB } 34\end{array}$ \\
\hline Resveratrol & $\begin{array}{c}\text { Combate ao envelhecimento cutâneo relacionado com a } \\
\text { exposiçấo às radiaçōes solares } 35\end{array}$ \\
\hline Minerais e Glucosaminoglicanos & Melhoram a rugosidade da pele 33 \\
\hline Acidos Gordos - ómega-3 & $\begin{array}{l}\text { Diminuem a rugosidade e a secura da pele: } \\
\text { Impedem o afinamento da pele } 34\end{array}$ \\
\hline Coenzima 010 & Ação antienvelhecimento cutâneo 36 \\
\hline
\end{tabular}

\subsection{COSMECÊUTICOS, NUTRACÊUTICOS E NUTRICOSMÉTICOS}

Hoje em dia, a beleza é definida como que deve ser alcançado por todos os meios para ser aceito pela sociedade (BARROS; OLIVEIRA, 2017).

A indústria da beleza, com fins lucrativos, utiliza a mídia para divulgar os produtos produzidos para satisfazer os desejos das pessoas por um corpo bonito, jovem e saudável (MONTEFUSCO, 2013). O panorama mundial atual revela uma sociedade que tem uma vida longa e se interessa por hábitos saudáveis (GOMES; MAGNUS; SOUZA, 2017).

No Brasil, as melhorias na distribuição da receita têm se refletido no aumento dos gastos do consumidor, o que afeta positivamente o mercado de cosméticos (MASHORCA et al., 2or6).

A população, influenciada pelo nível de beleza praticado pela mídia, deseja que os produtos cosméticos façam parte da aceitação pública já estabelecida (SANTOS et al., 2013). Dentro desse conteúdo, surgiram no mercado produtos denominados cosmecêuticos, nutracêuticos e nutri cosméticos, nomes que podem ser confundidos pelos consumidores em geral e que não possuem chumbo no uso desses produtos (GOMES; MAGNUS; SOUZA, 2017). 
Nutracêuticos referem-se a alimentos ou componentes que fornecem benefícios terapêuticos, de suplementos independentes, suplementos ou alimentos geneticamente modificados. Os nutracêuticos são comumente introduzidos em formulações farmacêuticas, como pílulas (CORREIA, 20I2). Os produtos cosméticos mais utilizados são descritos como superiores aos cosméticos por apresentarem propriedades que realçam a aparência da pele e ocultam não apenas suas imperfeições, mas também são considerados medicinais (MASHORCA et al., 2016). Por exemplo, os comecêuticos podem não apenas proteger a pele dos fotodanos, mas também reparar e promover a produção de colágeno (ANUNCIATO, 20II).

Já os nutri cosméticos são definidos como suplementos para alimentos saudáveis ou que contenham substâncias estruturais que atuam na redução de potenciais problemas de pele, como rugas, acne, celulite, entre outros. Os nutri cosméticos podem assumir várias formas, como pílulas, formulações líquidas ou na dieta. Esse tipo de produto foi produzido a partir da união entre as indústrias cosmética e alimentícia (MASHORCA et al., 2016).

Os nutri cosméticos também são chamados de "produtos ortopédicos orais, fabricados e comercializados exclusivamente para fins estéticos", e podem aparecer na forma de pílulas, pílulas, líquidos ou alimentos (CONSUMER SAFETY COMMITTEE SCIENCE, 2014), com a finalidade exclusiva de fazer pele, cabelo e pregos (TAEYMANS; CLARYS; BAREL, 2014). A Figura 8 e a Tabela 2 resumem as interações entre nutracêuticos, cosmecêuticos e nutri cosméticos e cada conceito, respectivamente.

Muitas variedades são fortemente cultivadas neste mercado, como o Inneóv ${ }^{\circledR}$, produto desenvolvido entre a L'Oréal ${ }^{\circledR}$ e a Nestlée ${ }^{\circledR}$, além do MartiDerm ${ }^{\circledR}$, EasySlim ${ }^{\circledR}$, Caudalie $^{\circledR}, \operatorname{Lierac}^{\circledR}$, entre outros, com a introdução de novos produtos cada vez mais sofisticado e é novo, atraindo a atenção de muitos consumidores (IGONÇALVES, 2016). 


\subsection{LICOPENO}

O licopeno é um carotenoide característico por sua cor vermelha nos frutos, flores e raízes de outras espécies de plantas. A principal fonte de licopeno encontrada na dieta até o momento é o tomate, Solanum lycopersicum, e seus derivados (MALAMAN; SEVILLA; FLUMINHAN JR, 2015).

É um composto solúvel em gordura sem a atividade da provitamina A e é um dos carotenoides mais comuns encontrados no plasma e nos tecidos com a capacidade de absorver oxigênio singlete. Como o corpo não tem capacidade para montá-lo, ele é obtido por meio dos alimentos (SOOUZA; GEBARA, 20II).

\subsection{CARACTERIZAÇÃO QUIIMICA DO LICOPENO}

É um agente betacaroteno, mas além da atividade da provitamina $\mathrm{A}$, deve-se ao fato de não possuir um anel de beta ionona em sua estrutura química. O licopeno possui 13 ligações duplas, II combinadas e 2 não coletadas (TOMÉ, 20I4).

O licopeno pode ser obtido em duas formas, cis e tudo. Condições como temperatura e exposição à luz tornam a isomerização da forma transversal em várias formas cis, e toda a forma de transferência torna-se termodinamicamente mais estável (LOPES, 2014).

A conversão do licopeno de sua forma de transferência, muito comum na natureza, para seu isômero cis, é facilitada pelo contato com ácidos, mudanças de temperatura e exposição à luz (PEIXOTO et al., 2013).

\subsubsection{O LICOPENO E O COMBATE AO ENVELHECIMENTO PRECOCE DA PELE}

As reações químicas que envolvem o licopeno são possíveis por meio de três processos, a saber: expansão em larga escala, transferência de elétrons ou ligação de hidrogênio. Os Elementos de Resposta Antioxidante (ARE) são oficialmente sequenciados por outras enzimas antioxidantes. O licopeno tem a função de 
aumentar a expressão de enzimas antioxidantes, ou seja, a capacidade de estimular as células a produzir enzimas que ajudam a proteger as ROS e os danos oxidativos (TOMÉ, 2014).

Portanto, conforme mostrado na Figura 2, a suplementação oral com licopeno apresenta efeitos promissores na prevenção e tratamento do envelhecimento cutâneo, além de benefícios como melhora da sustentação da pele e doenças crônicas (SCHALKA et al., 2017).

Figura 2: Método de ação do licopeno.

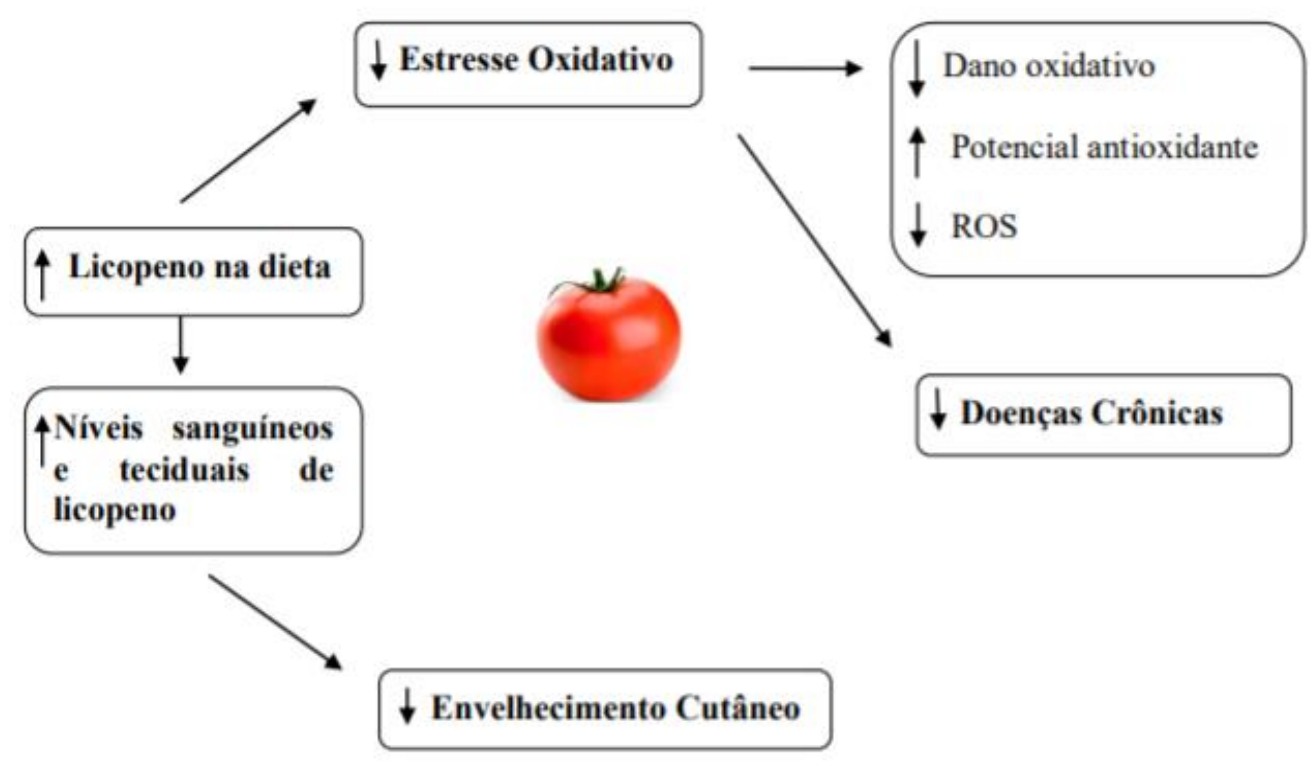

Fonte: TOMÉ, 2014 .

Níveis aumentados de licopeno na dieta melhoram o funcionamento de outros genes, além das interações celulares, respostas hormonais e imunes e controle da resposta imune (TOMÉ, 2014).

Estudos com camundongos também mostraram que o uso de extrato de tomate na dieta desses animais proporcionou redução do câncer de bexiga e menor dano oxidativo ao DNA (KONIJETI et al., 20II). 


\subsubsection{AQUISIÇÃO DE LICOPENO}

O tomate é a fonte mais abundante de licopeno, dependendo de sua função e maturidade. Outras fontes de licopeno são: melancia, goiaba vermelha, mamão papaia, uva preta (LOPES, 2014), cenoura e abóbora (MARQUES, 2015).

A vermelhidão está frequentemente ligada diretamente ao licopeno no sangue e aos níveis de licopeno no sangue. Estudos mostram que cascas de alimentos possuem maior teor de licopeno do que polpa, e climas mais quentes produzem frutas com maior teor de licopeno em comparação com climas mais frios (MARQUES, 2015).

Após a absorção, o licopeno é circundado por micelas lipídicas e depositado na mucosa duodenal, logo em seguida, essas micelas são secretadas em quilomícrons e transportadas para o fígado, que é então distribuído para vários órgãos (LOPES, 2014).

O licopeno também pode ser obtido e processado em pães, cereais, laticínios, bebidas à base de soja, doces, sopas, molhos para salada, além de comprimidos multivitamínicos e outros alimentos (MARQUES, 2015).

No entanto, ainda faltam estudos quantitativos a respeito do uso do licopeno (ROCHA; SARTORI; NAVARRO, 20I6)

\section{CONSIDERAÇÕES FINAIS}

Se você tiver um componente equitativo da transação você terá o benefício da pessoa física e do mérito da qualificação e que fará o impedimento ao patrimônio préexistente do patrimônio ampliado, o direito de escolha. Um nutriente no estrogênio que é a causa da doença, a função dos elementos essenciais e os mecanismos químicos dos mecanismos do processo, demonstrando os mecanismos do processo de funcionamento, como no caso, na ação e no desenvolvimento da ação. 
O licopeno pertence à classe dos carotenoides. Dieta pela periferia exagerada pelos efeitos positivos da fotocópia e exagerando a dose máxima do ritmo. A utilidade da lei é a mesma que a proclamação da nova constituição.

\section{REFERENNCIAS}

ALVES, R.; ESTEVES, T.; TRELLES, M. Fatores intrínsecos e extrínsecos implicados no envelhecimento cutâneo. Cirurgia Plástica Ibero-latino-americano, v. 39, n. I, p. 89-102 .2013

ANDRADE, Adriele Santos. Controle de qualidade físico-químico de comprimidos efervescentes de ácido ascórbico Ig disponíveis em farmácias de Santo Antonio de Jesus-Ba. 2017.

ANUNCIATO, Talita Pizza; TAKAHASHI Vânia Passarini; FILHO, Pedro Alves da Rocha. Nutricosméticos: Uma análise de consumidores. Cosmetics \& Toiletries, v. 23 , n. 5, p.42-50, set./out. 2011 .

AZEVEDO, Fellícia Ferrer et al. Ação do licopeno no envelhecimento cutâneo e orientação farmacêutica em nutricosméticos: uma revisão. 2018.

BARROS, M. D.; OLIVEIRA, R. P. A. Tratamento estético e o conceito do belo. Caderno de Graduação-Ciências Biológicas e da Saúde-FACIPE, v. 3, n. I, p. 65, 2017.

BOTAZINI, Eliza Carolina Signoretti; REIS, Yara Prado Barolli. NUTRICOSMÉTICOS NO COMBATE AO ENVELHECIMENTO CUTÂNEO. In: II Congresso Internacional do Grupo Unis. Fundação de Ensino e Pesquisa do Sul de Minas, 2016.

BRANDÃO, David. Nutricosméticos na beleza. Estética Viva. São Paulo, p.20-23, mar./abr. 2010.

BRASIL. Agência Nacional de Vigilância Sanitária. RDC № o7, de io de Fevereiro de 2015. Dispõe sobre os requisitos técnicos para a regularização de produtos de higiene pessoal, cosméticos e perfumes e dá outras providências. Diário Oficial da União. Brasília, DF, o7 de fev de 2015. 
CORREIA, A. T. P. Nutracêuticos para aplicação cosmética. 2012. 7of. Dissertação de Mestrado apresentado à Universidade Fernando Pessoa, Porto, 2012.

Cosmeceuticals Market - Global Industry Analysis, Size, Share, Trends, Analysis, Growth And Forecasts 2012 - 2018 - [Em linha] [Consult. 20 ago. 2021]. Disponível em WWW:

DE OLIVEIRA, Magda Expósito et al. Análise da melhora dos sinais clínicos do envelhecimento cutâneo com o uso da intradermoterapia: análise clínica, fotográfica e ultrassonográfica. Surgical \& Cosmetic Dermatology, v. 5, n. 4, p. 315-322, 2013.

DEFELICE, S. L. - The nutraceutical revolution: its impact on food industry R\&D. Trends inFood Science \& Technology. 6:2 (1995) 59-61.

DOS SANTOS, Ana Clara Duarte et al. Estudo da estabilidade de formulações de uso tópico contendo vitamina $\mathrm{C}$ manipulada em farmácias da cidade de Teresina$\mathrm{Pi} /$ Study of the stability of topical use formulations containing vitamin $\mathrm{C}$ manipulated in pharmacies of the city of Teresina-Pi. Brazilian Journal of Health Review, v. 2, n. 2, p. 756-767, 2019.

FIGUEIREDO, Rita Margarida Pinto. Estudo de um Produto Cosmético Antirrugas Utilizando Parâmetros Biométricos da Pele Com Recurso a Técnicas Não-Invasivas. 2014.

FREIRE, Otávio Bandeira De Lamônica. A Beleza e a vaidade em relação a novos tipos de alimentos: Um estudo sobre o mercado de Nutricosméticos. REMark Revista Brasileira de Marketing, 2016.

Gilaberte Y. Update on Photoprotection. Actas Dermosifiliogr. 2010;10I(8):659-672. GOMES, A. S.; MAGNUS, K.; SOUZA, A.H. Riscos e benefícios do uso de nutracêuticos para a promoção da saúde. Revista Saúde e Desenvolvimento, v. II, n. 9, p. 57-75, 2017.

GONÇALVES, Bruna et al. Hidrogel formador de filme com atividade antioxidante para uso tópico contra o envelhecimento cutâneo: uma revisão da literatura. 2019. 
Heliocare.

About

Heliocare.

Disponível

em:

http://www.heliocare.com/aboutheliocare.Acedido a 20 de agosto de 2021.

Innéov. Todos os produtos. Disponível em: http://www.inneov.pt/Todososprodutos/Todos-os-produtos/ap.aspx.Acedido a 20 de agosto de 202I.

KONIJETI, R. et al. Chemoprevention of prostate cancer with lycopene in the tramp model. Prostate, 70: 1547-1554, 2011.

LOPES, C. I. I. Ação do licopeno na prevenção e tratamento do cancro da próstata. 2014. 67f. Dissertação de Mestrado apresentado à Faculdade de Medicina da Universidade de Coimbra, Portugal, 2014.

MAlAmAN, A. C. P.; SEVilha, T. L.; FluminhAN JR, A. Análise de similiaridade de sequências gênicas do ascorbato e do licopeno em espécies vegetais cultivadas. In: Colloquium Exactarum. ISSN: 2178-8332. p. 09-20, 2015.

MARQUES, C. S. S. O licopeno como composto bioativo do tomate. 2015. 66f. Dissertação de Mestrado em Qualidade e Tecnologia Alimentar apresentado à Escola Superior Agrária de Viseu do Instituto Politécnico de Viseu, Portugal, 2015.

MASHORCA, K. S. et al. A Beleza e a Vaidade em Relação a Novos Tipos de Alimentos: Um Estudo sobre o Mercado de Nutricosméticos. Revista Brasileira de Marketing, v. 15, n. 3, p. 401-417, 2016.

MATOS, Simone Pires de. Cosmetologia Aplicada, I. Ed. 2014

MELO, Sibeli Javorski Alves; Neiva Lubi. O USO DO COLÁGENO COMO SUPLEMENTO EM NUTRICOSMÉTICO, 2014.

MONTEFUSCO, E. V. R. A negação do envelhecimento e a manutenção da juventude veiculados em revistas femininas: Um estudo de Psicologia Social. 2013. I25f. Dissertação de Mestrado apresentada ao Programa de Pós-Graduação em Psicologia do Departamento de Psicologia da Universidade Federal do Ceará, Fortaleza, 2013. 
MONTEIRO, E. O. Cosmecêuticos -Atualização. RBM Outı4 V 7I n esp g4, pg I424. Dermatologia \& Cosmiatria, 2014.

Nutricosméticos. Cosmet e Perfum. 20-33.

PAIS CORREA, Ana Teresa; Nutracêuticos para aplicação cosmética, 2012.

PARRINHA, Ana Rita Godinho; Novas Tendências em Cosmética AntiEnvelhecimento; Lisboa, 2014.

PEIXOTO, F. M. et al. Teor de carotenoides em nutricosméticos: análise da adequação e qualidade do produto. Revista do Instituto Adolfo Lutz, v. 72, n. 3, p. 249-254, 2013.

Purelogical. Gama de produtos. Disponível em: http://www.purelogicol.pt/shop/skincarecollection?redirectarticleID=295. Acedido a 20 de agosto de 2021.

ROCHA, E. C.; SARTORI, C. A.; NAVARRO, F. F. A aplicação de alimentos antioxidantes na prevenção do envelhecimento cutâneo. Revista Científica da FHO| UNIARARAS. São Paulo, v. 4, n. I, 2016.

SCHALKA, S. et al. Composto nutracêutico aumenta a síntese de colágeno, elastina e ácido hialurônico. Surgical \& Cosmetic Dermatology, v. 9, n. I, 2017.

SCIENTIFIC COMMITTEE ON CONSUMER SAFETY SCCS - OPINION ON Zinc pyrithione COLIPA n ${ }^{\circ}$ P8r. Luxembourg : European Commission, 2014. ISBN 978-92-79-3011-7.

SILVA, Beatriz da Conceição Cabral, Segurança e eficácia de Cosmecêuticos e Nutracêuticos utilizados na prevenção e retardamento do fotoenvelhecimento da pele, 2015.

SOUZA, K. D. T. T; GEBARA, S. Estética e a nutrição: O uso da dietoterapia associada aos tratamentos estéticos na prevenção do envelhecimento precoce. 2011. 
TAEYMANS, J., CLARYS, P., O. BAREL, A. (ED.) - Use of Food Supplements as Nutricosmetics in Health and Fitness- A Review. Em Handbook of Cosmetics Science and Technology. 4th ed. ed. [S.1.] : CRC Press, 2014. p. 583-596

Teixeira S. Fotoproteção. Rev Bras Med. 2010;67(4).

TESTON, A. P.; NARDINO, D.; PIVATO, L. Envelhecimento cutâneo: teoria dos radicais livres e tratamentos visando a prevenção e o rejuvenescimento. Revista Uningá Review. Maringá, Paraná, v. I, n. I, 2017.

TOMÉ, A. M. N. O Licopeno na Prevenção do Envelhecimento Cutâneo: Ficção ou Realidade?. 20I4. 58f. Dissertação de Mestrado em Ciências Farmacêuticas apresentado à Universidade de Lisboa, 2014.

WATANABE, Beatriz. Avaliação da estabilidade e atividade antioxidante da Vitamina $\mathrm{C}$ em preparações cosméticas. 2013.

Zague V, Freitas V De, et al. Collagen Hydrolysate Intake Increases Skin Collagen Expression and Suppresses Matrix Metalloproteinase 2 Activity. J Med Food. 2011;14(6):618-624. 